\title{
ИСПОЛЬЗОВАНИЕ ЦИФРОВЫХ ОБРАЗОВАТЕЛЬНЫХ ТЕХНОЛОГИЙ В ОБУЧЕНИИ ИЗОБРАЗИТЕЛЬНОМУ ИСКУССТВУ В ЭЛЕКТРОННОЙ ШКОЛЕ
}

\section{THE USE OF DIGITAL EDUCATIONAL TECHNOLOGIES IN TEACHING FINE ARTS IN E-SCHOOL}

\section{Zh. Amanzholova}

Summary: This article is devoted to the analysis of methods of teaching the fine arts in an electronic school using digital technologies in the educational process. In the modern educational space, this is a completely new phenomenon of modern culture, the specificity of which is due to the global information environment.

The article discusses the use of digital technologies in the methodology of teaching fine arts in an electronic school as an interactive addition to traditional forms of teaching fine arts, which allow not only to preserve all the advantages of traditional forms, but to fully use modern information technologies.

The effectiveness of the pedagogical potential in the process of using multimedia technologies in teaching the fine arts to schoolchildren is substantiated. The analysis of the pedagogical capabilities of some educational electronic portals, "Moscow electronic school" as factors of informatization of the education system is carried out. An example of the use of an interactive panel in fine arts lessons at the "Moscow Electronic School" as a condition for the development of the cognitive interest of schoolchildren is given.

The author comes to the conclusion that the use of digital technologies in the method of teaching fine arts in an electronic school for effective teaching of fine arts to children will increase motivation and involve students in interesting, active creative work, which will contribute to the development and harmonization of the child's personality.

Keywords: digital technologies, electronic educational resources, electronic teaching aids, multimedia capabilities, information technology, electronic school, teaching fine arts, digital educational environment, interactive panel.
Создав всемирные коммуникационные сети, человек окончательно превратил себя в часть чего-то большего, нежели он сам. Получив новое информационное измерение, человечество приобрело мощный потенциал для своего дальнейшего развития. В этом потенциале сокрыты как негативные, так и весьма позитивные преференции. И, как всегда на перекрестке развития, нам предстоит пережить Возрождение. Возрождение через искусство и культуру, через любовь к природе и духовные ипостаси [8, с.172].
Аманжолова Жаксыгул Сейткалиевна Аспирант, ФГБОУВО «Московский педагогический государственный университет»

Zhaklin2020@mail.ru

Аннотация: Настоящая статья посвящена анализу методик обучения изобразительному искусству в электронной школе с помощью применения в учебном процессе цифровых технологий. В современном образовательном пространстве это совершенно новый феномен современной культуры, специфика которого обусловлена глобальной информационной средой.

В статье рассматривается использование цифровых технологий в методике обучения изобразительному искусству в электронной школе в качестве интерактивного дополнения к традиционным формам обучения изобразительному искусству, которые позволяют не только сохранить все достоинства традиционных форм, но в полной мере использовать современные информационные технологии.

0босновывается эффективность педагогического потенциала в процессе применения мультимедиа технологий в обучении школьников изобразительному искусству. Проведен анализ педагогических возможностей некоторых образовательных электронных порталов, «Московской электронной школы» как факторов информатизации системы образования. Приводится пример использования интерактивной панели на уроках изобразительного искусства в «Московской электронной школе» как условия развития познавательного интереса школьников.

Автор приходит к выводу, что применение цифровых технологий в методике обучения изобразительному искусству в электронной школе для эффективного обучения детей изобразительному искусству позволит повысить мотивацию и вовлечь учащихся в интересную, активную творческую работу, что будет способствовать развитию и гармонизации личности ребенка.

Ключевые слова: цифровые технологии, электронные образовательные ресурсы, электронные учебные пособия, мультимедийные возможности, информационные технологии, электронная школа, обучение изобразительному искусству, цифровая образовательная среда, интерактивная панель.

Наиболее актуальное направление сегодняшней педагогики в области изобразительного искусства представлено разработкой инновационных средств, методов и технологий обучения, целью которых является развитие интереса обучающихся к изобразительному искусству. К числу таких технологий, имеющих значительный развивающий потенциал, можно отнести нынешние цифровые технологии с применением мультимедийных средств обучения.

Они отличаются от бумажных аналогов тем, что учи- 
теля имеют фактическую возможность более интересно, логично и концентрированно управлять процессом обучения, используя множество различных выразительных интерактивных наглядных средств, которые помогают в наибольшей степени задействовать познавательную, эмоционально-волевую сферы учащихся. Указанное, в свою очередь, содействует их более эффективному обучению и творческому развитию. Ученики при помощи цифровых технологий получают великолепный шанс учиться дистанционно, самостоятельно в любом месте в удобное время, имея только электронные устройства.

В современной ситуации развития образования, когда мы сталкиваемся с новыми вызовами и задачами, дистанционные образовательные технологии востребованы всеми. В глобальном эксперименте в условиях пандемии «приняло участие» все современное человечество - более 3 миллиардов обучающихся и обучающих. Глобальной системе образования, каждому учителю и каждому образовательному учреждению нужно извлечь из этого урок и понять плюсы и минусы дистанционных технологий. Но очевидно, что современное образование не будет больше таким, как до пандемии, и что роль дистанционных технологий не просто возросла. Они перевернули систему - новая образовательная революция произошла [4, с.24].

Основным видом информации, с которым учащиеся школы работают при изучении дисциплины «Изобразительное искусство» - это графическая информация. Возможности цифровых технологий при работе с этой информацией направлены как на применение имеющихся электронных образовательных ресурсов, эффективно подменяющих достаточно маленький запас иллюстративного материала, который есть в наличии в обычных школах, так и на освоение учениками средств и инструментария формирования и обработки графической информации [1, с. 338].

Исходя из потребностей школьного курса «Изобразительное искусство» и возможностей цифровых и коммуникационных технологий можно выделить следующие направления деятельности учителя и учащихся (рисунок 1) $[2$, c. 54]:

-самостоятельная разработка
учебно-методических
матерпалов курса;

-попск, каталогизация и
использование готовых
электронных образовательных
ресурсов;

-создание и редактирование пзображений с использованием графнческого редактора.

Рис. 1. Направления деятельности при использовании цифровых технологий в сфере обучения изобразительному искусству.
Для преподавания курса «Изобразительное искусство» учителю необходимо достаточно много наглядного материала. Поэтому ему нужно уметь находить, выбирать, оценивать и систематизировать иллюстрации, рисунки, графическую, текстовую и видеоинформацию. Современный инструментарий цифровых и коммуникационных технологий способен предоставить как учителю, так и учащемуся очень легкие в применении способы фиксации окружающей действительности, художественных произведений, декоративных изделий, изделий народного промысла, имеющихся в музеях и на выставках, такие как сканеры, цифровые фотоаппараты и видеокамеры.

В качестве преимуществ применения цифровых технологий в методике обучения изобразительному искусству в электронной школе можно отметить следующие:

- Наглядные пособия и мультимедийная продукция имеют специфический педагогический эффект. В частности, качество наглядности имеет особые свойства: оно более приближенное к действительности, демонстрирует состояние природы, выражений лиц, движения, формы и т.д.; доступное для фиксации не только художникам, но и непосредственно учащимся.

- Наличие возможности обработки и изменения полученных изображений: изменение размера и контрастности, добавление цвета, фильтрация цветовой и световой гамм. Такая методическая деятельность учителя активизирует учеников к ведению аналогичной деятельности. Исходя из результатов практики, ученики с огромным желанием находят и фиксируют на фото и видео экспозиции музеев, предметы народной культуры и продукты собственного творчества. Познание простых функций помогает им обрабатывать снимки, творчески выполнять домашние задания.

- Структура электронных образовательных ресурсов, выстроенная в виде отдельных элементов или файлов по блочно-модульному принципу, предоставляет возможность в простой форме осуществлять подачу учебного материала так, что ученик овладевает учебным материалом последовательно.

- Использование цифровых технологий в обучении воспитывает и развивает, прививает ученикам самостоятельность, преодоление сложностей.

- Применение цифровых технологий при обучении школьников изобразительному искусству оказывает положительное влияние на активизацию процесса обучения, существенно обновляя его, поддерживая требуемый уровень мотивации учащихся к изобразительному искусству. Они становятся неотъемлемой частью учебно-воспитательного процесса. 
Доктор педагогических наук, профессор Н.М. Сокольникова рекомендует использовать цифровые технологии в обучении с первого класса и даже раньше, тем самым формируя информационную культуру [10, с. 22].

Применяя цифровые технологии в методике обучения изобразительному искусству в электронной школе учащихся можно познакомить с возможностью сканирования и компьютерного редактирования собственных рисунков, обработки фотоизображений, составление нового изображения из готовых фрагментов (компьютерная аппликация). Встраивая готовые изображения в программу PowerPoint, педагоги и учащиеся могут создать иллюстративный материал, полученный изменением последовательности экранов в слайд-шоу [3, с. 112].

На сегодняшний день имеется большое разнообразие среди электронных учебных материалов по искусству (например: http://fcior.edu.ru ; http://www.openclass.ru). Они предоставляют следующие возможности (рисунок 2).

Инструментальные возможности цифровых технологий и программного обеспечения способствуют сосредоточению внимания школьников на определенных нюансах произведения, несущих специальную смысловую нагрузку. Более того, можно выделить светом, увеличить или рассмотреть объект с разных ракурсов. Это очень удобно при исследовании объемного объекта (например, скульптуры) или отдельных элементов картины.

Обратим внимание, что возможность виртуального видоизменения электронных источников информации, В отличии их печатных аналогов, более согласуется с особенностями мышления младших школьников в исследовании окружающей действительности [14, с. 74], в том числе и изобразительного искусства.

При начальном изучении изобразительного искусства предусмотрено ознакомление учеников с графическими редакторами и освоение простых форм редактирования изображений. В связи с чем получило развитие новое направление в изобразительном искусстве - цифровая живопись.
Однако, педагог в данном случае должен знать, как язык компьютерной графики, так и технологии и методику выполнения учениками рисунков и орнаментальных композиций в графическом редакторе. В примерной образовательной программе начальной школы (составитель Е.С. Савинов) в качестве распространенного и наглядного графического редактора для начального знакомства с элементами компьютерной графики рекомендуется редактор Paint. Простота и ясность этого редактора позволяет ученикам выполнять такие действия с объектами как поворот, вырезание, изменение контрастности, яркости, вырезание и добавление фрагмента, изменение размера, соединение нескольких графических изображений, наслаивание изображений [9, с. 32].

Применение указанного графического редактора на занятиях по изобразительному искусству согласуется и с учебными целями, поскольку его инструменты (кисточка, карандаш, резинка) и графические примитивы непосредственно соотносятся с их вещественными эквивалентами (карандаш, кисть, ластик, циркуль, лекала, линейка) при рисовании на бумаге. Также при наличии графических планшетов можно соотносить и проецировать собственные рисунки и рисунки детей в электронную форму с возможностью последующего видоизменения и трансформации [5, с. 110].

В настоящее время существуют разнообразные интересные и полезные интерактивные проекты по изобразительному искусству - видео-уроки, видео-лекции, электронные учебники, пособия, презентации, электронные справочники, энциклопедии и т. д.

Наибольшую популярность и востребованность получил Федеральный портал «Российское образование» [12]. Каждый желающий может воспользоваться его информационными ресурсами при наличии соответствующих технических средств.

По изобразительному искусству обучающие материалы на этом портале представлены в зависимости от возраста детей и тематики занятий. На сегодняшний день это самый посещаемый портал, что говорит о вос-

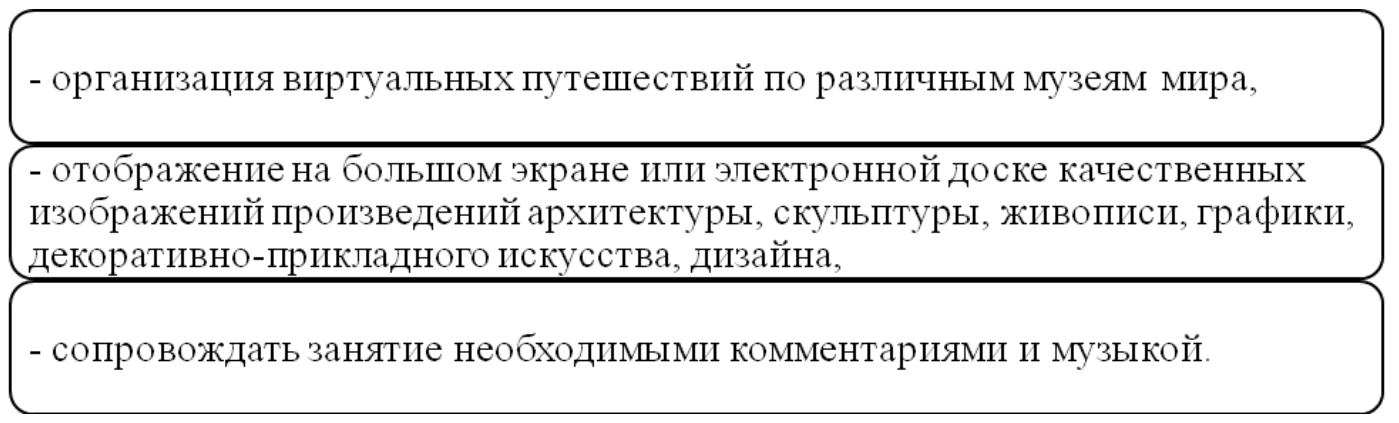

Рис. 2. Возможности электронных учебных материалов по искусству 
требованности электронно-образовательных и информационных ресурсов учителями, родителями, и детьми.

Следующим крупным инновационным образовательным проектом является «Российская электронная школа». Это информационная школа была создана для реализации качественного и доступного информационного обучения посредством применения в процессе обучения методически разработанных электронных образовательных ресурсов всеми участниками образовательного процесса: педагогическими работниками, учащимися, их родителями и всеми, желающими учиться.

На портале материал по изобразительному искусству изложен доступно и дополнительно предоставлено звуковое сопровождение, которое можно воспроизводить неоднократно.

Очень познавательные электронно-образовательные материалы по изобразительному искусству предоставляет МАДХО - международная ассоциация деятелей художественного образования [13].

Ассоциация существенное внимание уделяет вопросам обучения детей изобразительному искусству. На базе МАДХО разработана линейка инновационных образовательных ресурсов для разных возрастов - интерактивные видеолекции, видеоконференции, вебинары, круглые столы и т.д. Доступность, качество, живой звук, интересная подача материала от самых квалифицированных педагогов страны способствует ученикам быстро освоить ту или иную тему занятий по изобразительному искусству.

В «Московской электронной школе»на постоянной основе используются разнообразные мультимедиа технологии. Эффективность образовательного процесса при использовании разнообразных цифровых и мультимедиа технологий обеспечивается посредством вовлечения всех чувственных анализаторов учащихся в процессы восприятия и когнитивной переработки получаемой информации. Применение цифровых и мультимедиа технологий в образовательном процессе на уроках изобразительного искусства помогает более эффективно воспринимать информацию школьниками о сущности и специфике произведений искусств.

Наибольшую популярность среди цифровых технологий в нынешних электронных школах получила интерактивная доска. Она представляет собой панель с сенсорным экраном, которая выступает рабочей поверхностью для записей, показа обучающих фильмов (в т.ч. в 3D формате), видеотекстов, фотографий и пр. B литературе часто отмечается, что интерактивная доска представляет собой «методическое творчество педагога» и выступает сильным мотивационным и творческим стимулом для учеников [6, с. 47].

В «Московской электронной школе» в качестве методического инструментария, используемого на уроках изобразительного искусства с применением интерактивной панели, является программно-методический комплекс для интерактивной доски «Азбука искусства». Электронное пособие построено в виде виртуального музея, каждый из трех этажей которого посвящен определенной тематике. Школьника «сопровождают» три героя: Муза, Тимей и Художник. На первом этаже музея школьники знакомятся с Основами композиции и Введением в художественный образ. На втором этаже предлагается познакомиться с Линиями, цветом и стилями картин. На третьем этаже можно проверить свои знания в Экзаменационном кабинете; ознакомиться со всеми используемыми в пособии репродукциями, портретами и пейзажами в Комнате отдыха или Запасниках; познакомиться с незнакомыми определениями и терминами в Библиотеке или изучить историю русской иконописи на Факультативе. Все учебные материалы отличаются высокой интерактивностью, наглядностью и продуманным дизайном.

Таким образом, педагог использует активные и интерактивные методы обучения, отказываясь от уже малоэффективной пассивной методологии обучения. Ведущими в активной методологии обучения, согласно Е.В. Кузнецовой, становятся «целенаправленная активизация мышления обучающихся, достаточно длительное время вовлечения обучающихся в учебный процесс, самостоятельная творческая выработка решений, повышенная степень мотивации и эмоциональности, интерактивный характер» [7, с. 124].

Конечно, это лишь единичные примеры применения цифровых технологий в методике обучения изобразительному искусству в электронной школе, действующие в рамках российского общеобразовательного пространства. Имеются и частные авторские разработки [11, с. 102], которые успешно внедряются в образовательный процесс - это различные обучающие программы, презентации, методические разработки, выложенные на тех или иных сайтах по изобразительному искусству, помогающие детям осваивать азы творчества, начиная уже с младшего школьного возраста.

Анализ, проведенный в настоящей статье, позволяет прийти к следующим выводам. Применение цифровых технологий в методике обучения изобразительному искусству в электронной школе способствует не только качественному обновлению образования, но и правильному обращению детей с раннего возраста с информацией, воспитанию в них информационной культуры, поискового и познавательного интереса и активности, творческой любознательности, когда в свободном до- 
ступе можно «сходить» на выставку, «посетить» музей или «побывать» в мастерской знаменитого художника, а также самостоятельно проявить свои таланты и способности, общаясь с лучшими учителями страны.

Применение цифровых ресурсов в методике обучения изобразительному искусству, как наиболее интересного, наглядного, доступного и понятного для учащихся инновационного элемента обучения, согласованного с их эстетической и технологической избирательностью, позитивно влияет на процесс усвоения знаний и позволяет вывести сам учебный процесс на качественно более высокий уровень, так как дети с удовольствием работают и с обучающими программами, и с электронными пособиями, сами разрабатывают презентации, моделируют, проектируют и с огромным интересом и желанием относятся к выполнению заданий и упражнений с помощью цифровых технологий. Важно развивать это направление, потому что именно с помощью этих ресурсов возможно объединить, интегрировать, систематизировать и модернизировать весь учебно-образовательный процесс.

Итак, использование цифровых технологий на занятиях изобразительным искусством выступает для учащихся значимым инновационным средством художественно-творческого развития, эффективной инструментальной основой методологического комплекса формирования и развития интереса школьников к изобразительному искусству в условиях цифровой образовательной среды, отличным подспорьем в подготовке к практическим занятиям и инструментом эффективного сотрудничества всех субъектов образовательного процесса.

\section{ЛИТЕРАТУРА}

1. Акишина Е.М. Современные аспекты модернизации преподавания предметной области «Искусство» // Педагогика искусства. 2017. № 1. С. 138-144

2. Белов Д.И. Особенности обучения подростков живописи на основе традиций отечественной художественной школы: дисс. ... канд. пед. наук: 13.00 .02$. Москва, 2016.- 221 c.

3. Горбунова Г.А., Игнатьев С.Е. Интеграционные подходы в системе обучения изобразительному искусству в начальных классах // Наука и школа. 2015. № 6. С. $110-119$.

4. Даутова 0.Б., Крылова 0.Н. Педагогические технологии для старшей школы в условиях цифровизации современного образования: учебно-методическое пособие для учителей / 0.Б. Даутова, О.Н. Крылова. - Спб.: КАРО, 2020. - 176 с.

5. Зайцева С.А. Состояние и перспективы развития ИКТ-компетентности учителя начальных классов // Ярославский педагогический вестник, 2011. №2. С. 109-112

6. Кроткова И.Н. Интерактивная доска на занятиях французского языка // Научный поиск.2013. № 2.С. 46-50

7. Кузнецова Е.В. Применение активных методов обучения в учебном процессе в вузе // Актуальные вопросы подготовки современных медицинских кадров: материалы межрегиональной учебно-методической конференции 26 апреля 2018 года / Под ред. Е.Н. Касаткина, Н.С. Семенов, Н.Л. Никулиной. - Киров: ФГБОУ ВО Кировский ГМУ Минздрава России, 2018. - С. 124-130

8. Ломов С.П., Аманжолов С.А. Методология художественного образования: Учебное пособие. - М.: Прометей, 2011. - 188 с.

9. Руднев А.Ю., Тегин В.А. Разработка и использование электронных учебных изданий. - M.: Lennex Corp, 2012. - 168 c.

10. Сокольникова Н. М. Изобразительное искусство. 1-4 класс (CD). - М.: Астрель, 2014

11. Степанов В.Г., Борисова А.И. Зрительное восприятие и изобразительное искусство // Педагогика и психология образования. 2015. № 4. С. 100-108

12. Федеральный портал «Российское образование» [Электронный ресурс]// Режим доступа: http://resh.edu.ru/ (дата обращения: 08.11.2020)

13. Федеральный портал «Российская электронная школа» [Электронный ресурс]// Режим доступа: http://resh.edu.ru/ (дата 0бращения: 08.11.2020)

14. Шептуховский, М.В. Экологические аспекты профессиональной подготовки учителя начальных классов // Школа будущего. 2009. №1. С. 72-78.

(c) Аманжолова Жаксыгул Сейткалиевна (Zhaklin2020@mail.ru). 